Supporting Information

\title{
Construction of a ternary complexes-based DNA logic nanomachine for highly accurate imaging analysis of cancer cells
}

Chang Feng, ${ }^{\mathrm{a}, \mathrm{b}}$, Tianshu Chen ${ }^{\mathrm{a}}$, Dongsheng Mao ${ }^{\mathrm{a}}$, Fan Zhang ${ }^{\mathrm{a}}$, Bo Tian ${ }^{\mathrm{a},}$, Xiaoli Zhu

${ }^{a}$ Center for Molecular Recognition and Biosensing, School of Life Sciences, Shanghai University, Shanghai 200444, P. R. China.

bSchool of Medicine, Shanghai University, Shanghai 200444, P. R. China.

*E-mail: botian@shu.edu.cn 
Table S1. Sequences of DNA oligonucleotides used in this work

\begin{tabular}{|c|c|c|c|}
\hline \multicolumn{2}{|l|}{ oligonucleotide } & \multirow{2}{*}{$\begin{array}{l}\text { Sequence }\left(5^{\prime}-3^{\prime}\right) \\
\text { GCAGTTGATCCTTTGGATACCCTGG }\end{array}$} & \multirow{2}{*}{ Modification } \\
\hline Blocked & $\mathrm{BA}$ & & \\
\hline aptamer (BA) & $\mathrm{BA}^{\prime}$ & GCAGTTGATCCTTTGGATACCCTGG & 5'-FAM \\
\hline \multirow{7}{*}{$\begin{array}{l}\text { Primer-aptamer } \\
\qquad \text { (PA) }\end{array}$} & PA1 & $\begin{array}{l}\text { CACTACAGAGGTTGCGTCTGTCCCACGTTGTCATGG } \\
\text { GGGGTTGGCCTGTTTTTTTTGGAGGGTGGGACTGCA } \\
\text { ATATCAAAGGATCAACTGC }\end{array}$ & \\
\hline & PA1' & $\begin{array}{l}\text { CACTACAGAGGTTGCGTCTGTCCCACGTTGTCATGG } \\
\text { GGGGTTGGCCTGTTTTTTTTGGAGGGTGGGACTGCA } \\
\text { ATATCAAAGGATCAACTGC }\end{array}$ & $\begin{array}{l}5 '-\mathrm{Cy} 5, \quad 3{ }^{\prime}- \\
\text { BHQ }\end{array}$ \\
\hline & PA2 & $\begin{array}{l}\text { CACTACAGAGGTTGCGTCTGTCCCACGTTGTCATGG } \\
\text { GGGGTTGGCCTGTTTTTTTTGGAGGGTGGGACTGCA } \\
\text { AATACCAAAGGATCAACTGC }\end{array}$ & \\
\hline & PA3 & $\begin{array}{l}\text { CACTACAGAGGTTGCGTCTGTCCCACGTTGTCATGG } \\
\text { GGGGTTGGCCTGTTTTTTTTGGAGGGTGGGACTGCA } \\
\text { ATATGTATCCAAAGGATCAACTGC }\end{array}$ & \\
\hline & PA4 & $\begin{array}{l}\text { CACTACAGAGGTTGCGTCTGTCCCACGTTGTCATGG } \\
\text { GGGGTTGGCCTGTTTTTTTTGGAGGGTGGGACTGCA } \\
\text { ATATATTAGGATCAACTGC }\end{array}$ & \\
\hline & PA5 & $\begin{array}{l}\text { CACTACAGAGGTTGCGTCTGTCCCACGTTGTCATGG } \\
\text { GGGGTTGGCCTGTTTTTTTTGGAGGGTGGGACTGCA } \\
\text { ATATTTTTAGATCAACTGC }\end{array}$ & \\
\hline & PA6 & $\begin{array}{l}\text { CACTACAGAGGTTGCGTCTGTCCCACGTTGTCATGG } \\
\text { GGGGTTGGCCTGTTTTTTTTGGAGGGTGGGACTGCA } \\
\text { ATATTTTTATATCAACTGC }\end{array}$ & \\
\hline \multicolumn{2}{|c|}{ Circular template (CT) } & $\begin{array}{l}\text { TCTCTAGCAGTCCCACCCTCCAACCACCAAGCCTCA } \\
\text { GCTACACGAATTGCCGAACGCACGCGATCCGCATG } \\
\text { TGGAAAA }\end{array}$ & \\
\hline \multicolumn{2}{|l|}{ FAM-Probe } & ACCAAGCCTCAGCTACACGAATT & 5'-FAM \\
\hline
\end{tabular}


A

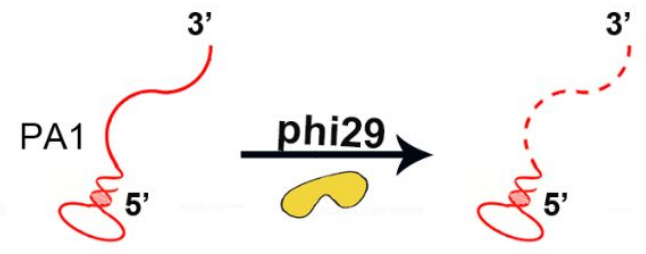

B

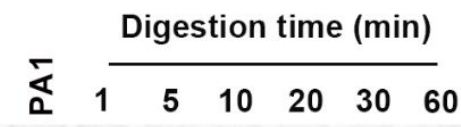

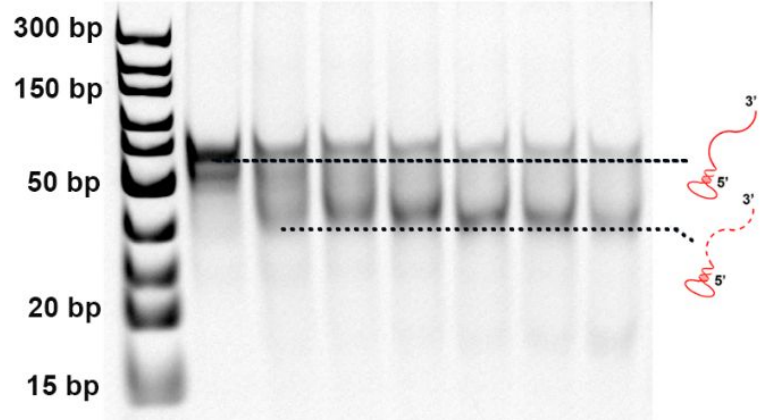

$10 \mathrm{bp}$

Figure S1. (A) Schematic diagram of the digestion of PA1 by phi29 DNA polymerase. (B) Digestion of $1 \mu \mathrm{M}$ PA1 by phi29 DNA polymerase for 0-60 min.

A

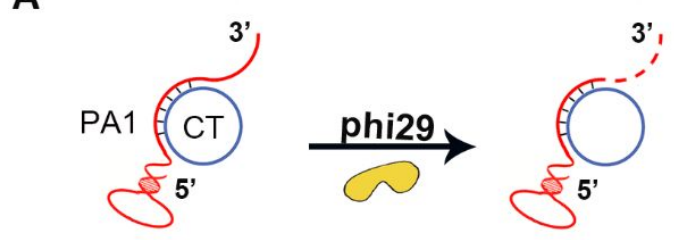

B
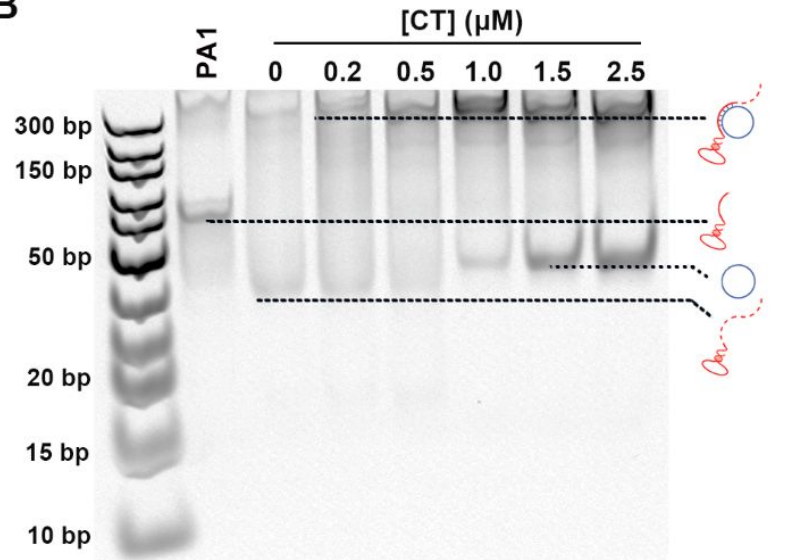

Figure S2. (A) Schematic diagram of the digestion of PA1-CT by phi29 DNA polymerase. (B) Digestion of $1 \mu \mathrm{M}$ PA1 by phi29 DNA polymerase in the presence of $0-2.5 \mu \mathrm{M} \mathrm{CT}$. 


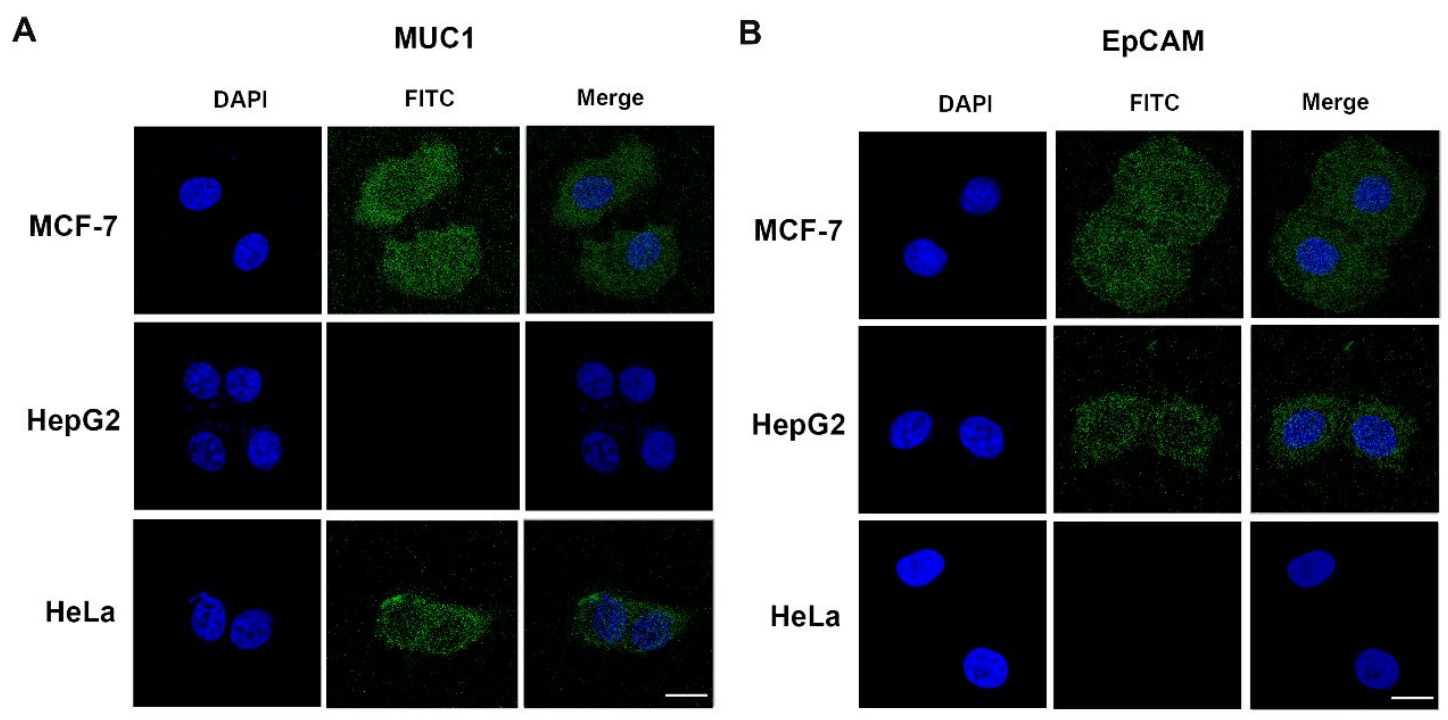

Figure S3. (A) Immunofluorescence of mucin (MUC1) from three cell lines (B) Immunofluorescence of epithelial adhesion molecules (EpCAM) from three cell lines. Scale bar $=20 \mu \mathrm{m}$.

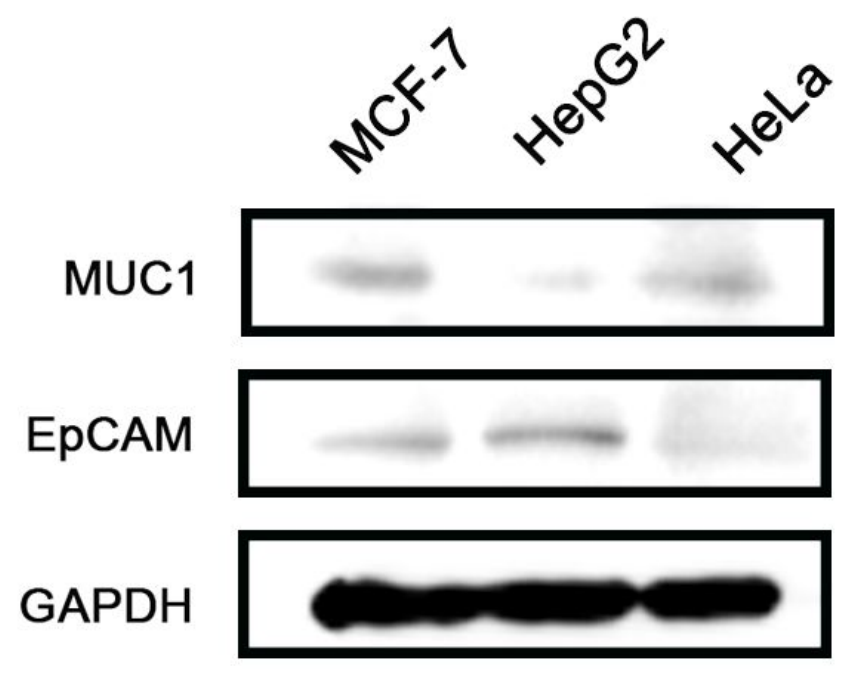

Figure S4. Western blotting results of MUC1 and EpCAM expression from three cell lines. 


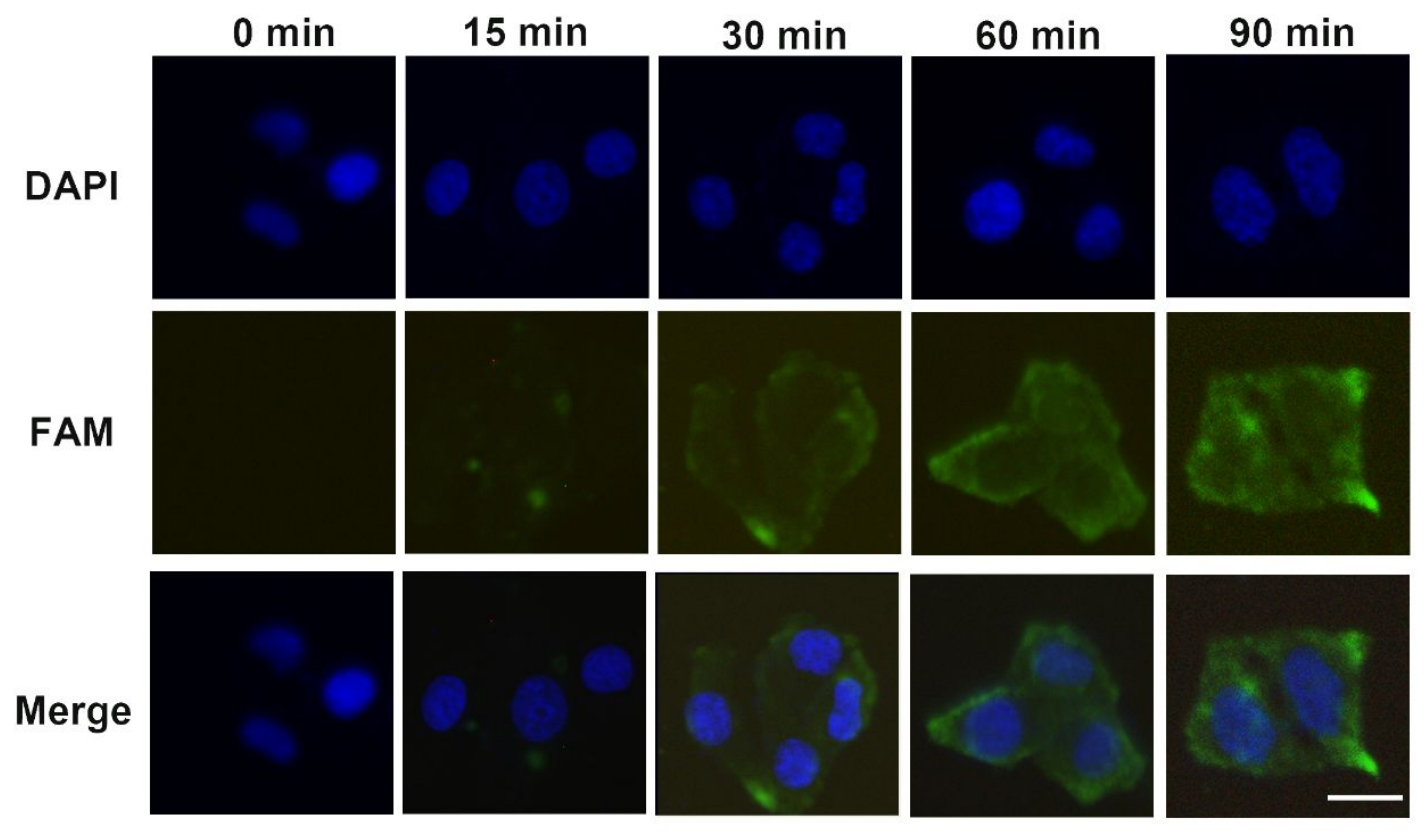

Figure S5. Fluorescence microscopy images of MCF-7 cells incubating with DNA nanomachine for different time (0-90 min). Scale bar $=20 \mu \mathrm{m}$.

A

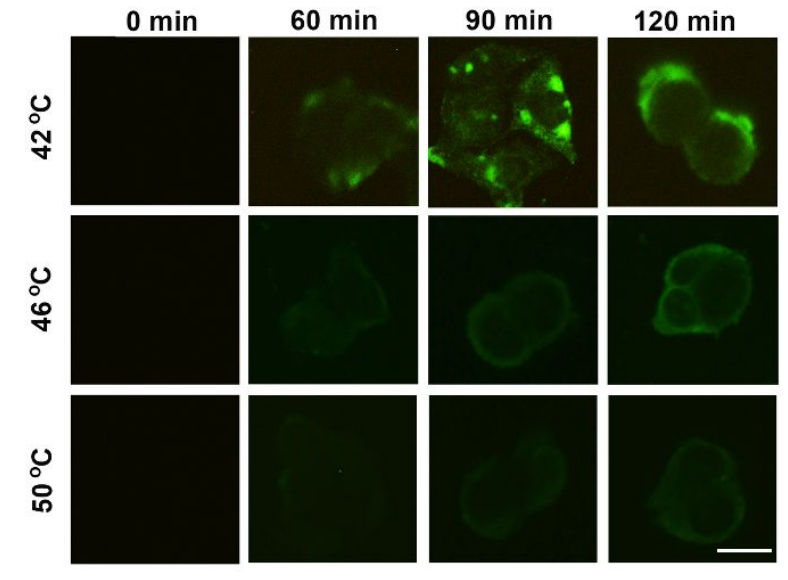

B

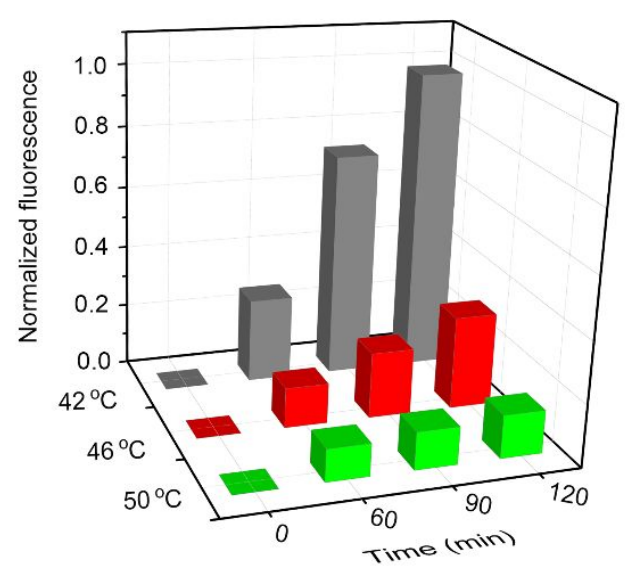

Figure S6. (A) Fluorescence microscopy images and (B) fluorescence intensity statistics of different rolling circle amplification time after the interaction of DNA nanomachine with the cell membrane surface. Scale bar $=20 \mu \mathrm{m}$. 


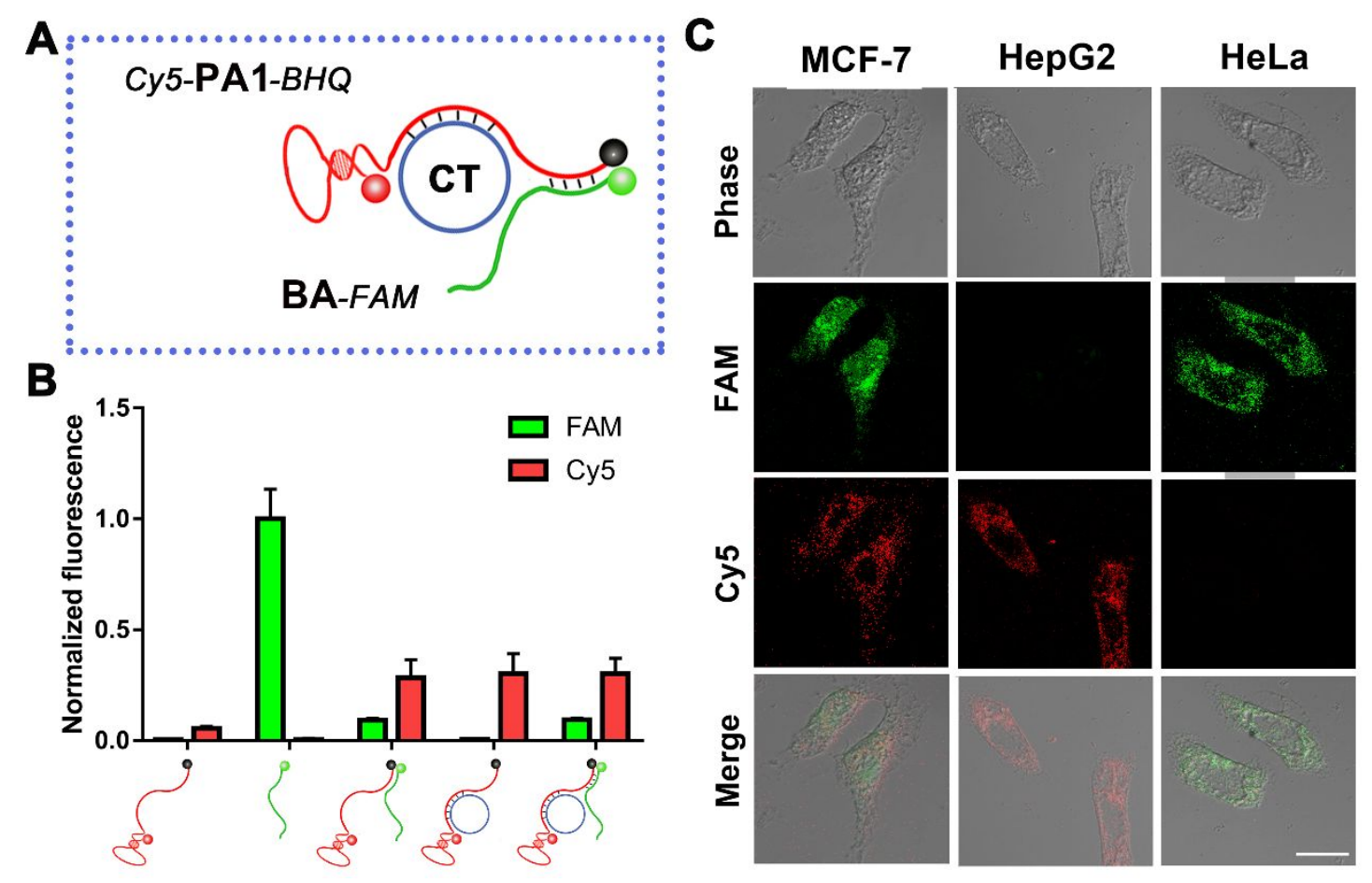

Figure S7. (A) Schematic diagram of fluorophores labeled DNA ternary complex. (B) Fluorescence intensity analysis of assembly of fluorophores labeled DNA ternary complex. (C) Confocal laser scanning microscopy images of three cell lines incubating with fluorophores labeled DNA nanomachine. Scale bar $=20 \mu \mathrm{m}$. 


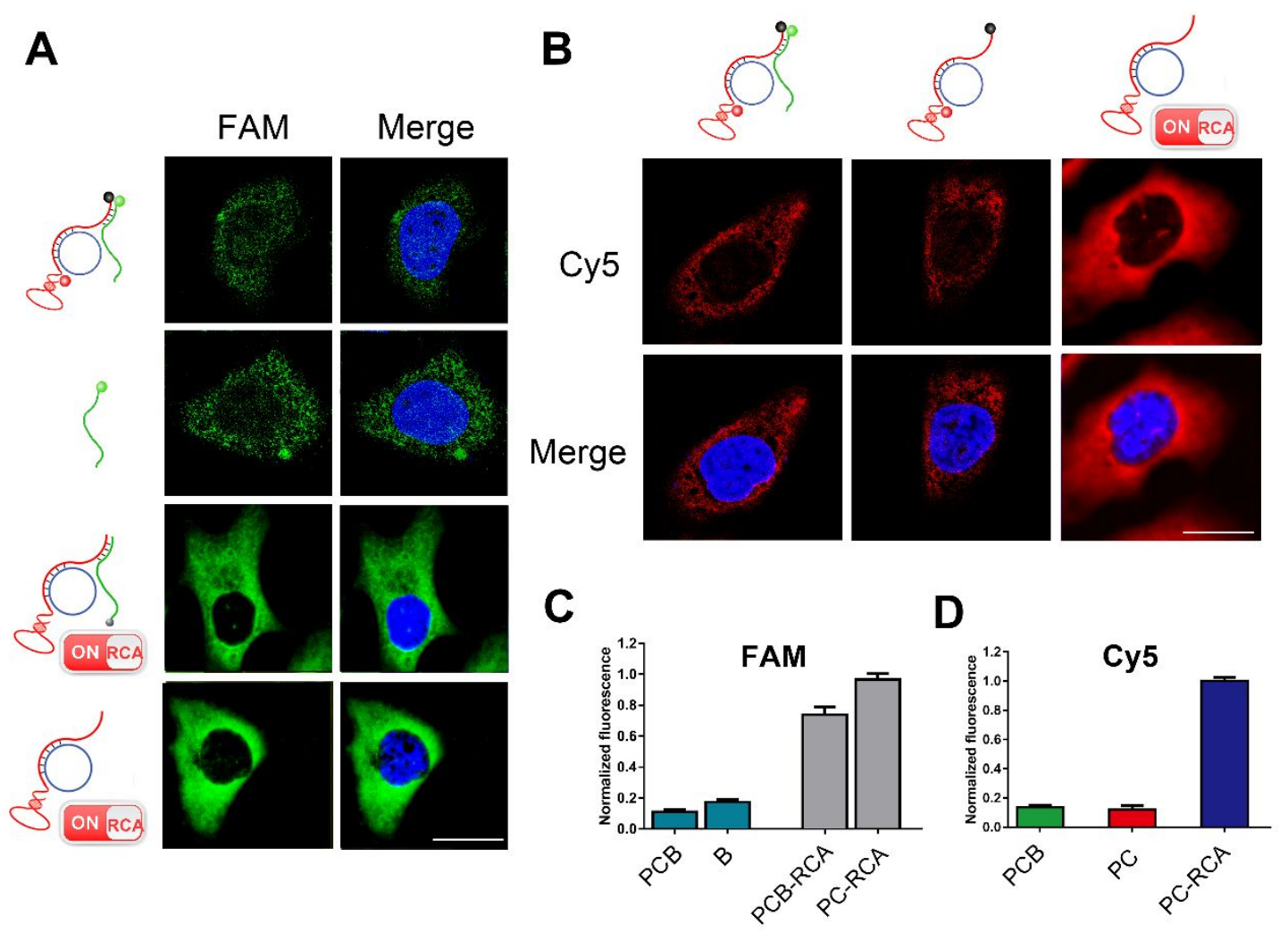

Figure S8. Study on the amplification efficiency of logic gate-responsive DNA nanomachine. Confocal laser scanning microscopy images of MCF-7 cells incubating with different DNA assembly (A) green fluorescence (FAM) (B) red fluorescence (Cy5). (C-D) Fluorescence intensity statistics of cell imaging from (A) and (B) by ImageJ software. Scale bar $=20 \mu \mathrm{m}$. 